Article

\title{
Application of sodium titanate nanotubes doped with vanadium (VNaTNT) as a heterogeneous catalyst for oxidation of sulfides at room temperature
}

\author{
Mohammad Ali Dadvar, Razieh Fazaeli* \\ Department of Chemistry, Shahreza Branch, Islamic Azad University, 86145-311, Iran
}

\section{A R T I C L E I N F O}

Article history:

Received 31 December 2015

Accepted 4 February 2016

Published 5 April 2016

\section{Keywords:}

Sulfide

Sulfoxide

Sulfone

Supported vanadia catalyst

Nanotube

\section{A B S T R A C T}

A heterogeneous titanate nanotube (TNT) catalyst containing $\mathrm{TiO}_{2}, \mathrm{Na}$, and $\mathrm{V}$ has been synthesized and used in the chemoselective oxidation of sulfides to the corresponding sulfoxides in the presence of $30 \% \mathrm{H}_{2} \mathrm{O}_{2}$ in water. Some of the advantages of our method include excellent yields, heterogeneous conditions, simplicity, compatibility with a variety of functionalities, and ease of isolation of the products. Fourier transform infrared spectroscopy, X-ray diffraction, scanning electron microscopy, transmission electron microscopy, and $\mathrm{N}_{2}$ adsorption were used for structural and textural characterization of the catalyst (VNaTNT).

(C) 2016, Dalian Institute of Chemical Physics, Chinese Academy of Sciences. Published by Elsevier B.V. All rights reserved.

\section{Introduction}

Sulfoxides and sulfones [1], of which some are important commodity chemicals and pharmaceuticals [2], are most commonly synthesized by the straightforward oxidation of sulfides. This transformation has been carried out by various methods [3-7]. The use of $\mathrm{H}_{2} \mathrm{O}_{2}$ as the final oxidant offers the advantages that it is a cheap, environmentally benign, and readily available reagent and produces water as the only by-product [8]. It is worth noting that metal catalysts are essential for the production of sulfoxides in high yields and selectivities. There are several reports on some metal-containing catalysts, such as $\mathrm{V}$ [9], Ti [10], Cu [11], Ag [12], Fe [13], Bi [14], and W [15] for the oxidation of sulfides to sulfoxides. Unfortunately, most of these reagents are not satisfactory for medium- to large-scale synthesis because of the low content of effective oxygen, the formation of environmentally unfavorable co-products, and high cost.
Among all transition-metal oxides, $\mathrm{TiO}_{2}$ is the most extensively studied, making it one of the most investigated compounds in materials science. Bulk $\mathrm{TiO}_{2}$ is known to be a very useful non-toxic, environmentally friendly, corrosion-resistant material, it is frequently used in paint, white pigments, and sunblocks [16]. $\mathrm{TiO}_{2}$-based nanotubes have attracted attention because of their potential application as highly efficient photocatalysts [17], in lithium ion batteries [18], in photovoltaic cells [19], and in environmental applications [20]. Sol-gel processing of $\mathrm{TiO}_{2}$ has been extensively investigated, and modern processes have been developed to refine and control the stability, as well as the phase formation, of the colloidal precursors [21]. Sodium trititanate nanotubes have recently been synthesized using a method proposed by Refs. [22,23], via hydrothermal treatment of the titania precursor with concentrated $\mathrm{NaOH}$ aqueous solution (10 mol/L).

Vanadium has been shown to play an important role in oxidation reactions. For example, V-SBA-15, V-MCM-41, 
V-MCM-48, and V-MCF are some interesting V-containing mesoporous silica oxidation catalysts with uniform pore size and high surface area that offer a large concentration of accessible and well-defined active centers, often incorporated into the silica framework [24-29].

In this article, we report on an alcohol impregnation method for the synthesis of ordered sodium trititanate nanotubes (NaTNT) doped with vanadium (VNaTNT) by $\mathrm{NaOH}$ and $\mathrm{NH}_{4} \mathrm{VO}_{3}$ ((4-13) mol\%). The composition and crystallinity of these structures were determined by powder X-ray diffraction (XRD), scanning electron microscopy (SEM), transmission electron microscopy (TEM), N2 adsorption-desorption analysis, and thermal gravimetric (TG) analysis. The catalytic activity of VNaTNT is reported for the oxidation of sulfides with $\mathrm{H}_{2} \mathrm{O}_{2}$ (Scheme 1).

\section{Experimental}

Chemicals used were all of reagent grade. Reaction courses and product mixtures were monitored by thin layer and gas chromatographies. A Perkin Elmer Spectrum 65 spectrophotometer was used to obtain infrared spectra (400-4000 $\left.\mathrm{cm}^{-1}\right)$ from $\mathrm{KBr}$ pellets. $\mathrm{Cu} K_{\alpha}(0.154056 \mathrm{~nm})$ radiation with automatic control was used to obtain powder XRD patterns on Bruker D8 ADVANCE and PW1830 instruments. Adsorption/desorption of nitrogen at liquid nitrogen temperature was used to determine Brunauer-Emmett-Teller (BET) specific surface areas and pore volumes of the catalysts with a Micromeritics BELSORP mini II instrument. The samples were outgassed at $350{ }^{\circ} \mathrm{C}$ for $12 \mathrm{~h}$ under a vacuum of $1 \times 10^{-4} \mathrm{~Pa}$ prior to the adsorption measurements. Catalyst pore sizes were obtained from the peak positions of the distribution curves determined by the adsorption branches of the isotherms. A Joel JEM 2010 scan transmission electron microscope was used to obtain transmission electron micrographs. To perform the TEM measurements, the sample was suspended in ethanol and supported on a carbon coated copper grid. A Shimadzu, MPC-2200 $\mathrm{UV}-\mathrm{Vis}$ spectrophotometer operating within the range of 190-900 $\mathrm{nm}$ at a resolution of $2.0 \mathrm{~nm}$ was used to obtain DRUV spectra.

\subsection{Preparation of $V(x) N a T N T$}

VNaTNT catalysts were prepared by an alcohol impregna-

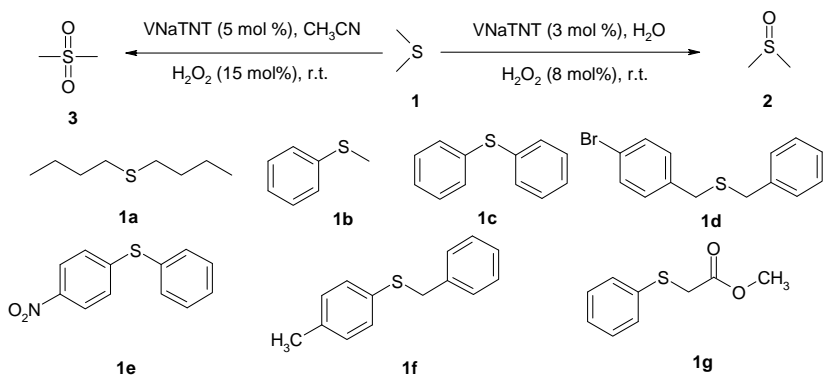

Scheme 1. Oxidation of sulfides (1) to sulfoxides (2) and sulfones (3) in the presence of VNaTNT catalyst. tion method. A methanol solution of $\mathrm{NH}_{4} \mathrm{VO}_{3}$ to achieve a final $\mathrm{V}$ content of (4-16) wt\% was contacted with the $\mathrm{NaTiO}_{2}$ support at $60{ }^{\circ} \mathrm{C}[22,23]$, and the methanol was rotary evaporated until complete dryness. The catalysts were then dried overnight in air at $120{ }^{\circ} \mathrm{C}$, followed by calcination at $400{ }^{\circ} \mathrm{C}$ for $4 \mathrm{~h}$, and the catalysts are denoted as $\mathrm{V}(x)$ NaTNT, where the $x$ is the $\mathrm{V}$ mass fraction (\%).

\subsection{Synthesis of sulfoxides and sulfones}

$\mathrm{H}_{2} \mathrm{O}_{2}$ (8 mmol) was added in one portion to a stirred suspension of the selected sulfide ( $1 \mathrm{mmol}$ ) and VNaTNT heterogeneous catalyst in water $(5 \mathrm{~mL})$. The resulting slurry was then stirred at room temperature for $30 \mathrm{~min}$. Ethanol $(10 \mathrm{~mL})$ was used to filter off and wash the catalyst. Ethyl acetate $(5 \mathrm{~mL})$ was added and the resulting solution was dried on anhydrous sodium sulfate and the solvents removed in vacuo to afford the crude product. This was then purified by column chromatography using silica gel and 10\% EtOAc in hexane as the eluent to afford pure sulfoxide. Sulfones were synthesized by a similar method using $5 \mathrm{~mol} \%$ of VNaTNT in $\mathrm{CH}_{3} \mathrm{CN}$.

\section{Results and discussion}

\subsection{Physico-chemical characterization}

Fig. 1 shows Fourier transform infrared (FT-IR) spectra of the NaTNT, V(4)NaTNT, and V(13)NaTNT samples. The vibrational mode observed at $896 \mathrm{~cm}^{-1}$ in the spectrum of the NaTNT reference is assigned to stretching of the Ti-O bonds from a distorted $\mathrm{TiO}_{6}$ octahedron whose oxygen is unshared [24]. The wavenumber of this vibrational mode increases from 896 in NaTNT to $908 \mathrm{~cm}^{-1}$ in V(13)NaTNT. This confirms incorporation of vanadium into the trititanate structures. Crystalline $\mathrm{V}_{2} \mathrm{O}_{5}$ is formed in the VNaTNT samples, as implied by the appearance of a typical band of $\mathrm{V}_{2} \mathrm{O}_{5}$ at ca. 970-976 $\mathrm{cm}^{-1}$. This suggests that the vanadium species are isolated in the VNaTNT samples, or at least highly dispersed on the TNT surface.

Fig. 2 shows XRD patterns of sodium titanate nanotubes NaTNT and VNaTNT. The results indicate that the NaTNT sam-

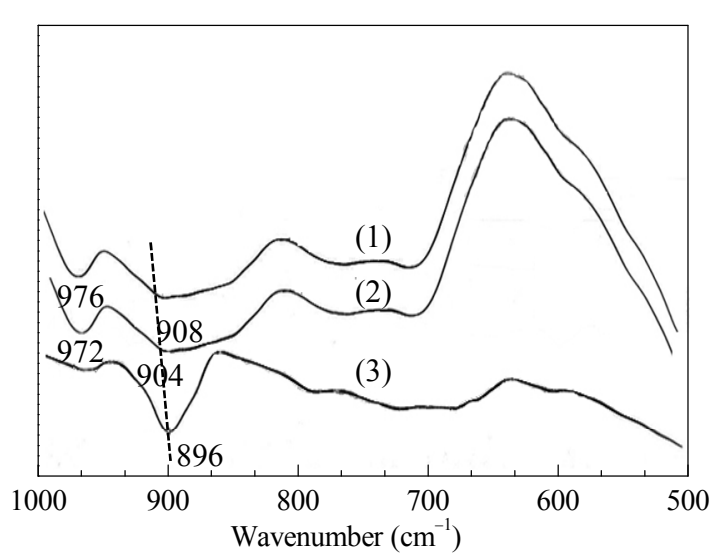

Fig. 1. FT-IR spectra of NaTNT and $V(x)$ NaTNT materials with two different $x$ values. (1) V(13)NaTNT; (2) V(4)NaTNT; (3) NaTNT. 


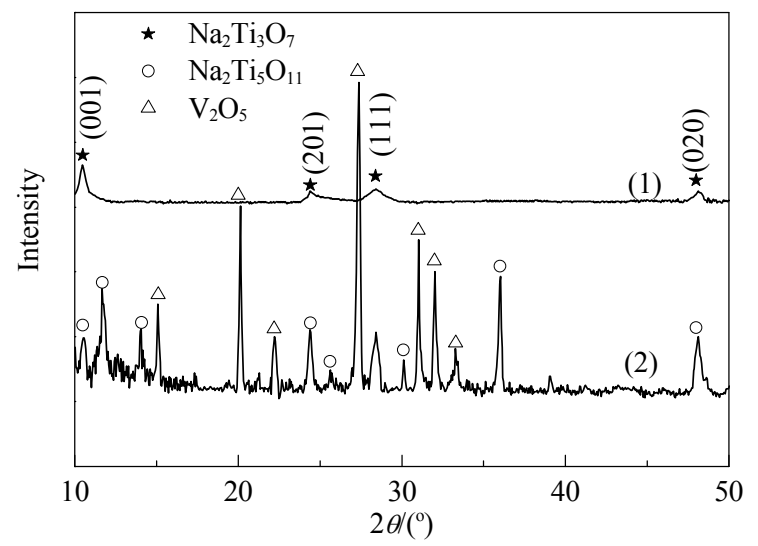

Fig. 2. XRD patterns of (1) NaTNT and (2) VNaTNT.

ples studied show good crystallinity and display characteristic peaks at $2 \theta=10.5^{\circ}, 24.2^{\circ}, 28.4^{\circ}$, and $48.2^{\circ}$, commonly associated with monoclinic layered sodium trititanate $\left(\mathrm{Na}_{2} \mathrm{Ti}_{3} \mathrm{O}_{7}\right.$, JCPDS-ICDD card 31-1329). These correspond to the (001), (201), (111), and (020) crystal planes, respectively.

Fig. 2(2) shows XRD pattern of VNaTNT. The results indicate that the VNaTNT samples show good crystallinity and display the characteristic peaks for $\mathrm{Na}_{2} \mathrm{Ti}_{3} \mathrm{O}_{7}, \mathrm{Na}_{2} \mathrm{Ti}_{5} \mathrm{O}_{11}$, and $\mathrm{V}_{2} \mathrm{O}_{5}$. The crystalline phases of $\mathrm{Na}_{2} \mathrm{Ti}_{3} \mathrm{O}_{7}$ and $\mathrm{Na}_{2} \mathrm{Ti}_{5} \mathrm{O}_{11}$ are generally considered characteristic for titanate nanotubular structures $[24,25]$. The presence of sodium in the interlayer spaces of the trititanate structure is confirmed by the presence of a peak at about $2 \theta=10.5^{\circ}[26]$.

A number of new sharp reflections are observed along with the signals corresponding to the $\mathrm{Na}_{2} \mathrm{Ti}_{3} \mathrm{O}_{7}$ phase, and this can be ascribed to the presence of different layered sodium titanates $\left(\mathrm{Na}_{2} \mathrm{Ti}_{5} \mathrm{O}_{11}\right)$ with a monoclinic lattice. Conversion of TNTs to larger nanostructures, such as nanoribbons and nanorods [27], is suggested by the appearance of the $\mathrm{Na}_{2} \mathrm{Ti}_{5} \mathrm{O}_{11}$. This is in good agreement with the SEM images (Fig. 3).
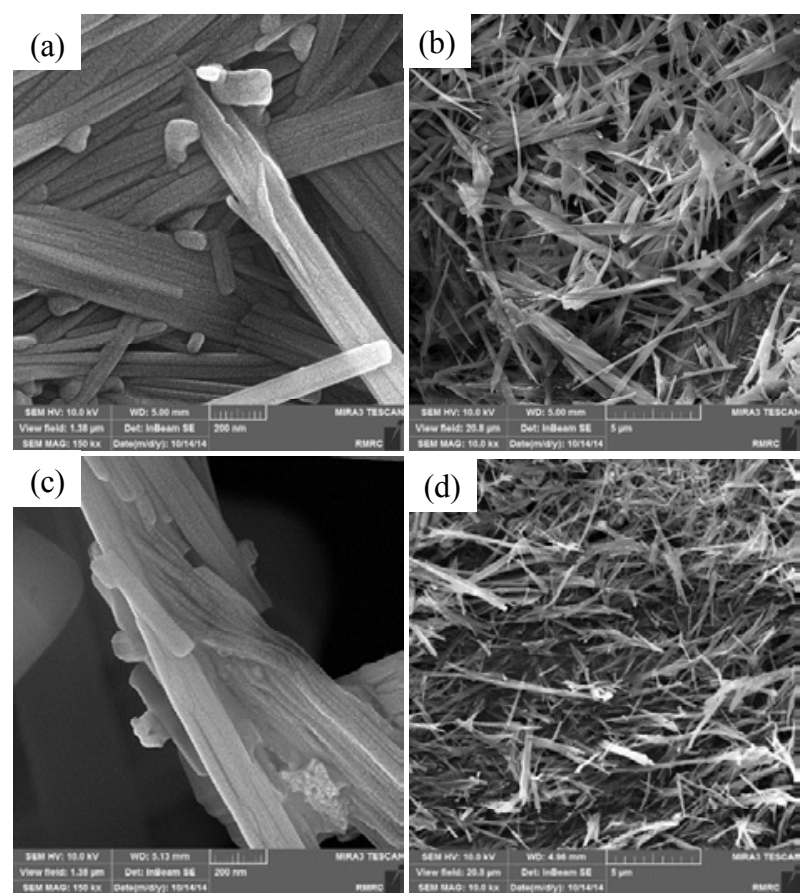

Fig. 3. SEM images of (a, b) V(4)NaTNT and (c, d) V(13)NaTNT.

Fig. 3 shows the SEM images of V(4)NaTNT and $\mathrm{V}(13) \mathrm{NaTNT}$ catalysts. $\mathrm{V}(x) \mathrm{NaTNT}$ exhibits aggregation of regular tube-shaped particles, commonly observed in pure titanate nanotube material [28]. The external diameter size of the nanotubes become smaller and the particles tend to aggregate after increasing the $\mathrm{V}$ loading from $4 \%$ to $13 \%$, as indicated by the SEM micrographs.

Fig. 4(a) shows the SEM-EDX spectrum of the V(13)NaTNT sample, which shows the presence of $\mathrm{V}, \mathrm{Na}, \mathrm{Ti}$ and $\mathrm{O}$ as elements in the V(13)NaTNT structures. According to the energy-dispersive X-ray (EDX) spectrum and its data in Table 1, it can be concluded that a sufficient amount of $\mathrm{Na}$ and $\mathrm{V}$ was
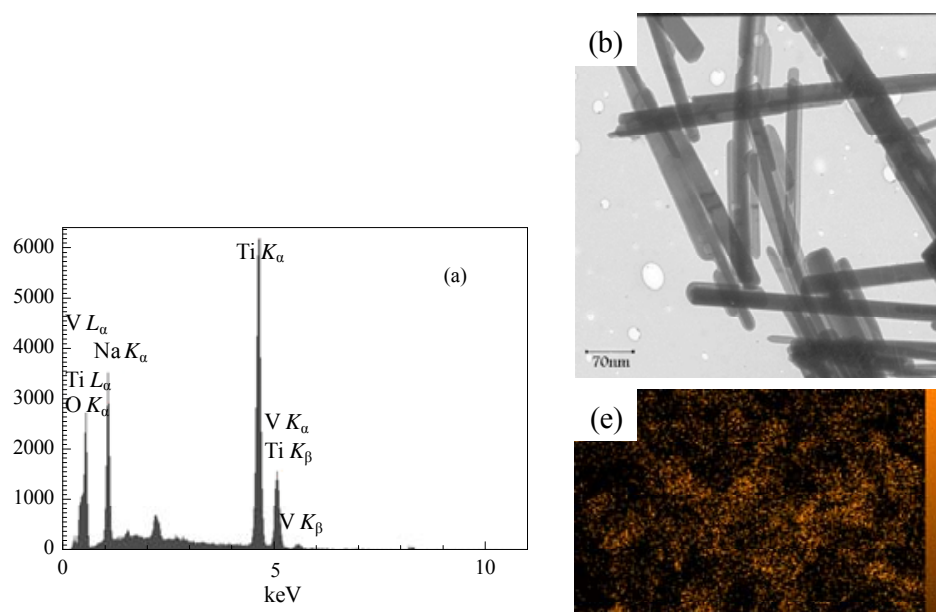

(c)
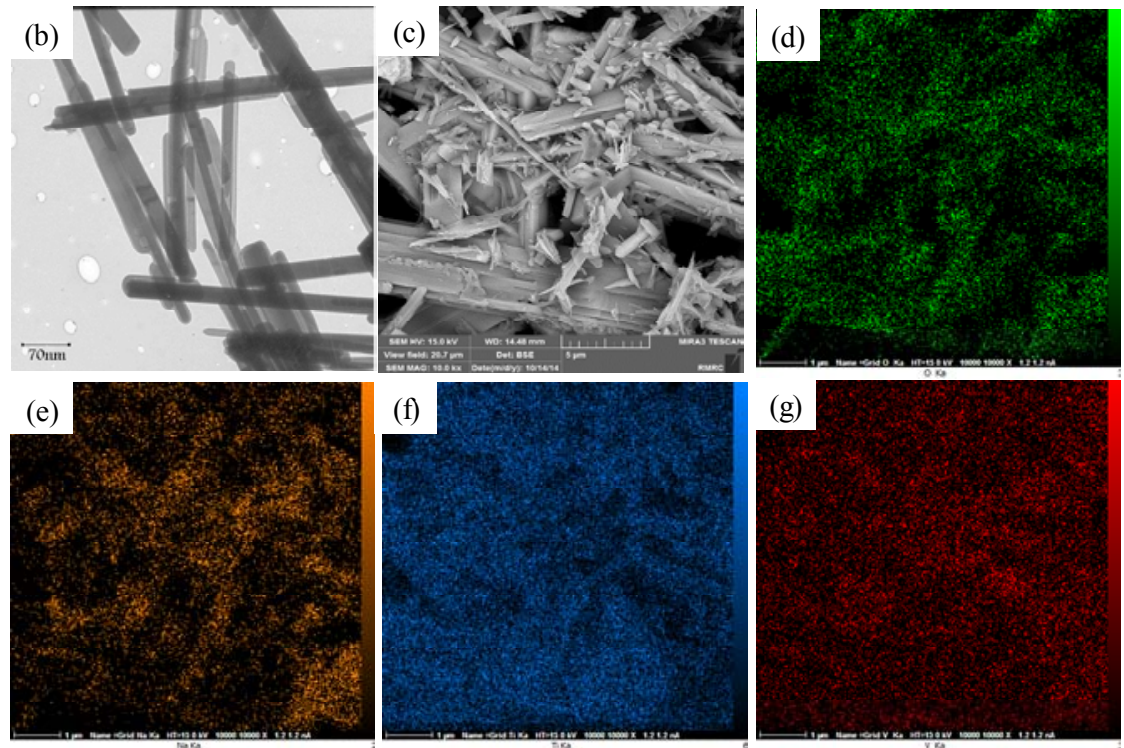

Fig. 4. (a) EDX-SEM and (b) TEM image of V(13)NaTNT, (c-g) SEM-EDX micrographs and distribution maps of elements in V(13)NaTNT. Particles rich in $\mathrm{O}$ (green), $\mathrm{Na}$ (orange), Ti (blue), and $\mathrm{V}$ (red) are present. 
Table 1

Effect of different conditions in the oxidation of diphenyl sulfides to sulfoxides after $0.5 \mathrm{~h}$.

\begin{tabular}{lcccc}
\hline Entry & Catalyst & $x / \%$ & $\mathrm{H}_{2} \mathrm{O}_{2}:$ sulfide & Yield $^{\mathrm{a}}(\%)$ \\
\hline 1 & - & - & $8: 1$ & 3 \\
2 & $\mathrm{TNT}$ & 3 & $8: 1$ & 11 \\
3 & $\mathrm{~V}_{2} \mathrm{O}_{5}$ & 3 & $8: 1$ & 23 \\
4 & $\mathrm{~V}_{2} \mathrm{O}_{5} / \mathrm{TiO}_{2}$ & 3 & $8: 1$ & 38 \\
5 & $\mathrm{NaTNT}$ & 3 & $8: 1$ & 27 \\
6 & $\mathrm{~V}(4)$ NaTNT & 3 & $8: 1$ & 66 \\
7 & $\mathrm{~V}(7)$ NaTNT & 3 & $8: 1$ & 75 \\
8 & $\mathrm{~V}(13)$ NaTNT & 3 & $8: 1$ & 87 \\
9 & $\mathrm{~V}(15)$ NaTNT & 3 & $8: 1$ & 80 \\
10 & $\mathrm{~V}(13)$ NaTNT & 3 & $8: 2$ & 98 \\
11 & $\mathrm{~V}(13)$ NaTNT & 4 & $8: 2$ & 85 \\
12 & $\mathrm{~V}(13)$ NaTNT & 5 & $8: 2$ & 64 \\
\hline
\end{tabular}

a Isolated yields.

loaded into the NaTNT. Fig. 4(b) shows TEM images of $\mathrm{VNa} / \mathrm{TiO}_{2}$. The VNaTNT sample was found to include nanotubular structures, either as random groups or aligned bunches. Elemental mapping has been performed for $\mathrm{V}, \mathrm{Na}, \mathrm{Ti}$, and $\mathrm{O}$, together with SEM imaging, EDX mapping (Fig. 4(c-g)), and EDX linear scanning of VNaTNT (Fig. 5), to check the uniformity of the elemental composition and distribution throughout the VNaTNT samples. The components are heterogeneously distributed throughout the TNT, as shown by EDX maps and linear scans.

Fig. 6 shows the $\mathrm{N}_{2}$ adsorption-desorption isotherms and Barret-Joyner-Halenda (BJH) pore size distributions of VNaTNT. A typical type-IV adsorption isotherm with a remarkable hysteresis loop is shown by VNaTNT. This confirms the presence of meso- and macropores. The shape of the $\mathrm{N}_{2}$ adsorption-desorption isotherms of VNaTNT (Fig. 6(a)), as well as their hysteresis loops, are similar to those previously reported for sodium titanate nanotubes synthesized from low surface area anatase precursors [28-30]. The pore size distribution curves (Fig. 6(b)) show that the sample contains three types of pores. The first type may be ascribed to a smaller portion of mesopores (about 3-5 nm in diameter) attributed to the nanotubes. The second type (about $10-15 \mathrm{~nm}$ in diameter) can be ascribed to the parallel assembly of the nanotubes, and the third type (about $35 \mathrm{~nm}$ in diameter) may result from randomly assembled nanotubes [23,28,29,31].

The thermal behavior of the NaVTNT is illustrated in Fig. 7(a). TG profile displays two mass loss events, as observed. The initial mass loss of $2.21 \%$ was observed at temperatures below $125{ }^{\circ} \mathrm{C}$ as a result of the loss of physically absorbed water. The second mass loss of $2.77 \%$ was between 230 and $570{ }^{\circ} \mathrm{C}$ (mostly at around $430{ }^{\circ} \mathrm{C}$ ), which can be attributed to the removal of unhydrolyzed isopropoxide ligands bonded in the titanium [32-34]. Approximately $95.02 \%$ of the starting mass remained after the second stage. The applicability of the VNaTNT across a wide temperature range is demonstrated by the TGA results.

A DRUV-Vis spectrum of the VNaTNT sample is shown in Fig. 7(b). The spectrum shows one intense absorption band at $247 \mathrm{~nm}$. This band is attributed to charge transfer transitions associated with $\mathrm{O}^{2-}$ to $\mathrm{V}^{5+}$ [35]. Indeed, this band closely resembles that found for $\mathrm{NH}_{4} \mathrm{VO}_{3}$ [36], indicating an isolated tetrahedral environment of $\mathrm{V}^{5}$ in the VNaTNT matrix, which is in good agreement with the literature [37]. On the other hand, the band at $247 \mathrm{~nm}$ may also be assigned to a distorted tetrahedral arrangement of $\mathrm{V}^{5+}$ (as a result of immobilizing/anchoring on
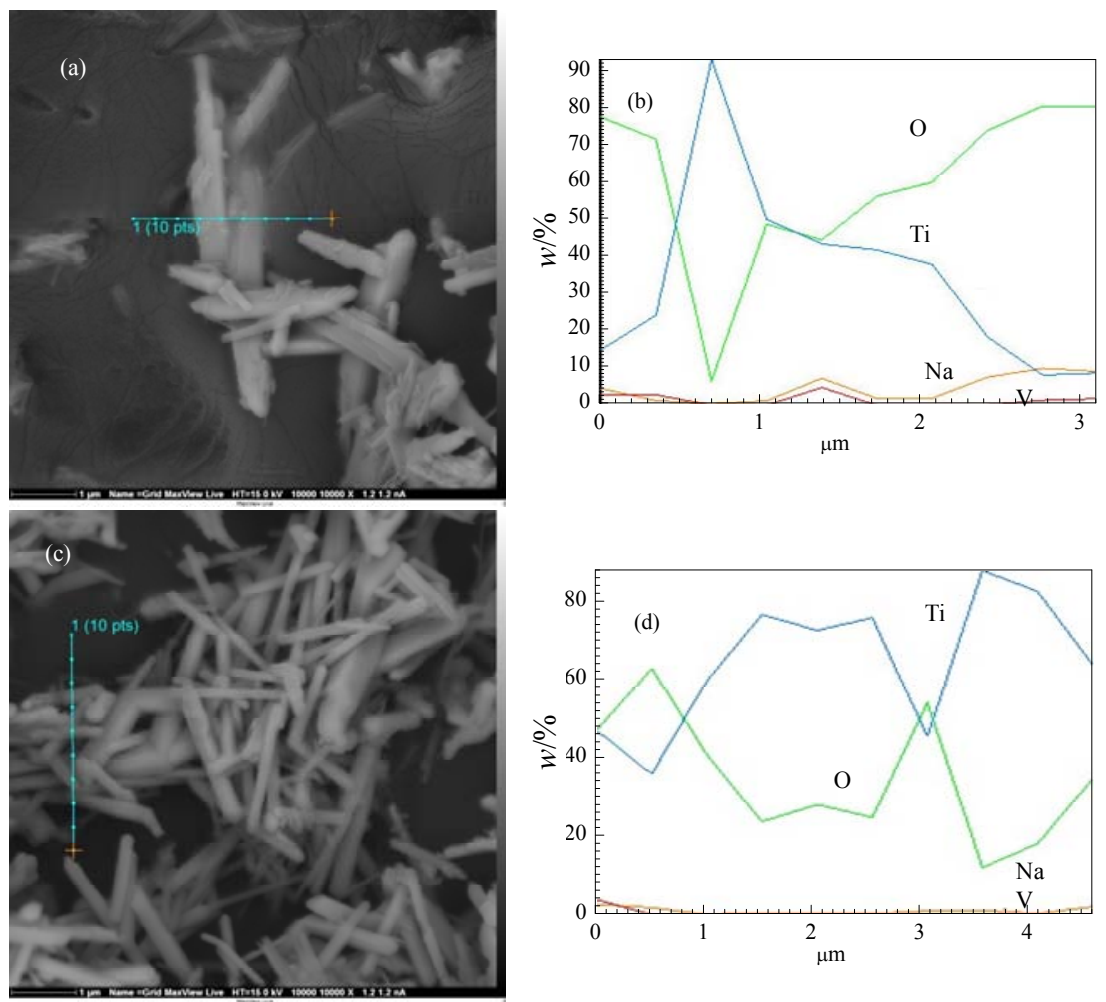

Fig. 5. SEM image and EDX linear scan along VNaTNT (a, b) fresh catalyst, and (c, d) reused catalyst after the sixth run. 

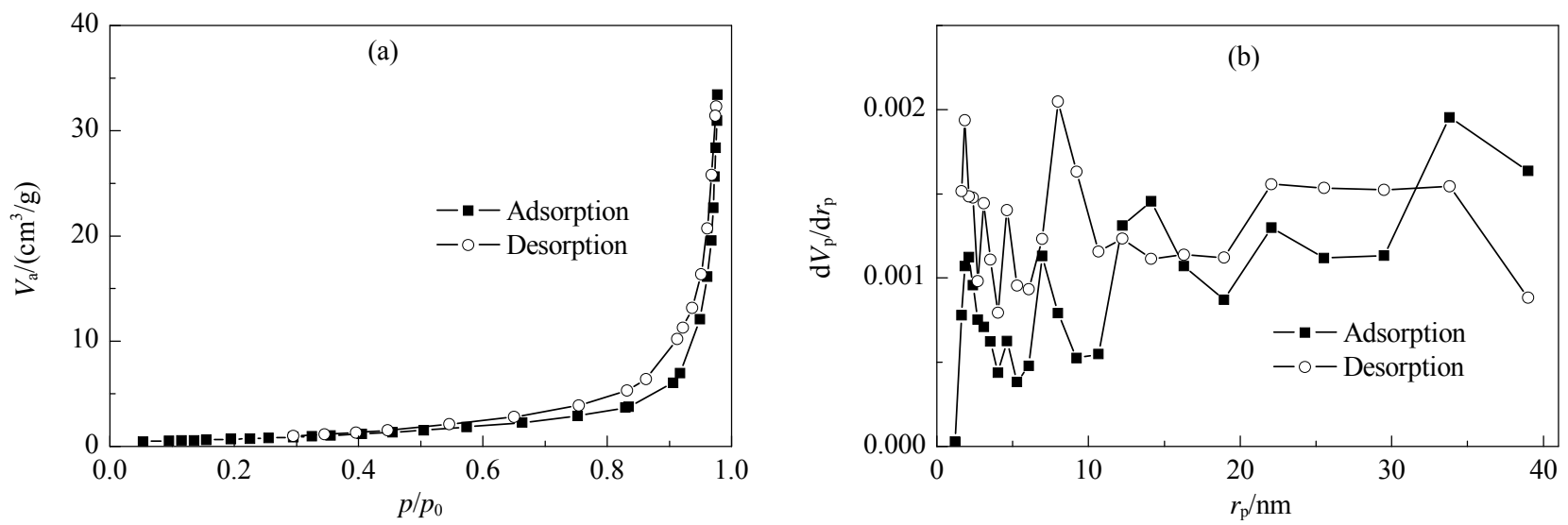

Fig. 6. (a) $\mathrm{N}_{2}$ adsorption-desorption isotherms and (b) pore size distributions calculated by the BJH method of V(13)NaTNT.
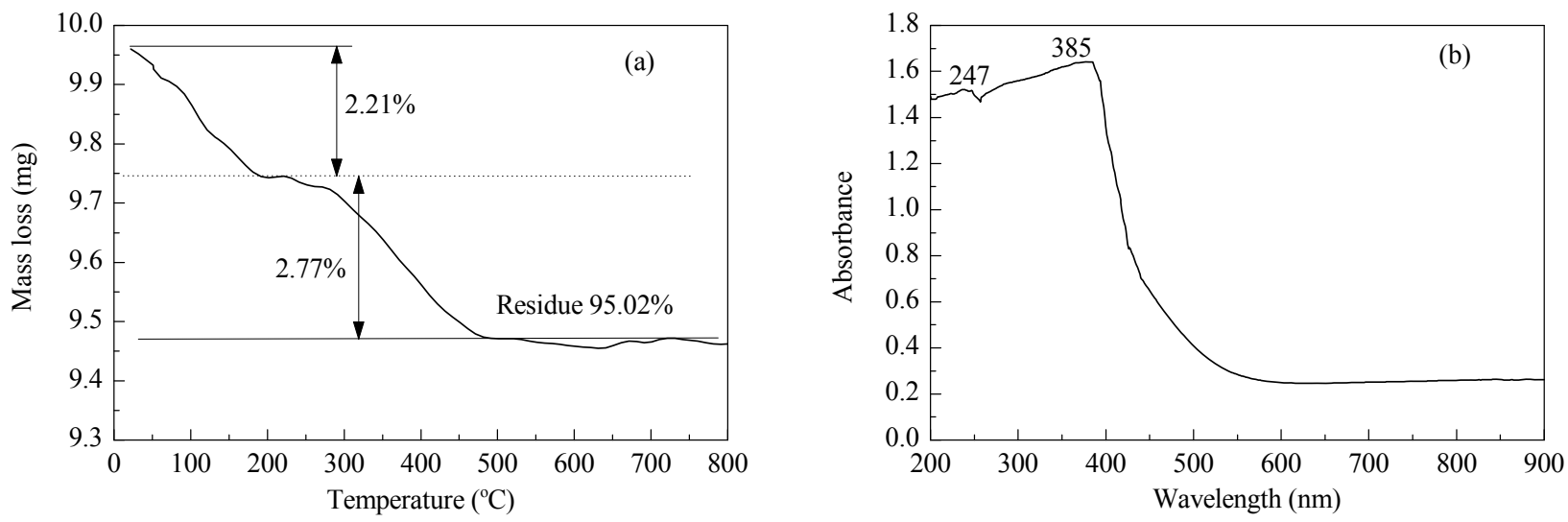

Fig. 7. (a) TG curve and (b) DRUV-Vis spectrum of V(13)NaTNT.

the pore windows of the TNT), in a similar manner to that reported for various vanadium-loaded/grafted amorphous/mesoporous silica materials $[37,38]$. The fundamental absorption edge of $\mathrm{TiO}_{2}$ appeared in the UV region at about 385 $\mathrm{nm}$ [39].

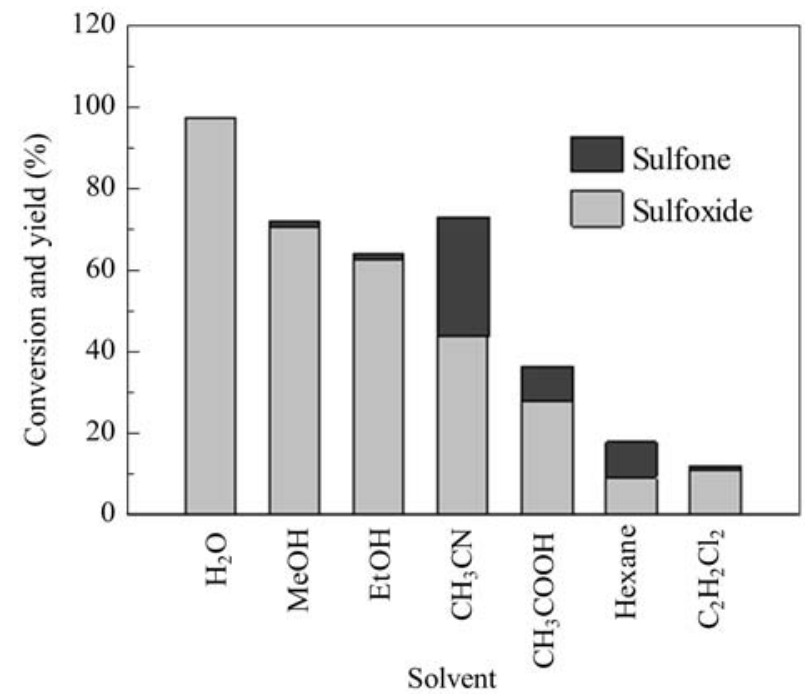

Fig. 8. Solvent effect on the conversion rate and selectivity of diphenyl sulfide oxidation using $\mathrm{H}_{2} \mathrm{O}_{2}$ catalyzed by V(13)NaTNT.

\subsection{Catalytic activity}

\subsubsection{Oxidation of sulfides to sulfoxides and sulfones}

Oxidation was carried out in methanol, $n$-hexane, dichloromethane, acetonitrile, ethanol, acetone, and $\mathrm{H}_{2} \mathrm{O}$ to check the feasibility of the VNaTNT system in an organic medium (Fig. 8). Solvents with high hydrogen bonding capacity, such as methanol and water, favor the formation of sulfide with high chemoselectivity [40], as clearly indicated in Table 2 and in

Table 2

Oxidation of sulfides to sulfoxides and sulfones using the $\mathrm{V}(13) \mathrm{NaTNT} / \mathrm{H}_{2} \mathrm{O}_{2}$ system.

\begin{tabular}{lcc}
\hline \multirow{2}{*}{ Sulfide } & \multicolumn{2}{c}{ Yield $^{\mathrm{a}}(\%)$-Time $(\mathrm{h})$} \\
\cline { 2 - 3 } & ${\text { Sulfoxide } \mathbf{2}^{\mathrm{b}}}^{\mathrm{b}}$ & Sulfone $\mathbf{3}^{\mathrm{c}}$ \\
\hline 1a & $98-0.5$ & $96-1.5$ \\
1b & $98-0.5$ & $97-1.5$ \\
1c & $98-1.0$ & $98-2.0$ \\
1d & $98-1.0$ & $98-1.5$ \\
1e & $98-1.2$ & $92-2.0$ \\
1f & $96-1.2$ & $92-2.0$ \\
1g & $92-1.8$ & $86-3.0$ \\
\hline
\end{tabular}

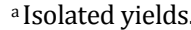

b Reaction conditions: Sulfide ( $2 \mathrm{mmol}), \mathrm{H}_{2} \mathrm{O}_{2}$ (8 mmol), V(13)NaTNT (3 mol\%), $\mathrm{H}_{2} \mathrm{O}(5 \mathrm{~mL})$, r.t..

c Reaction conditions: Sulfide (2 mmol), $\mathrm{H}_{2} \mathrm{O}_{2}$ (15 mmol), V(13)NaTNT (5 mol\%), $\mathrm{CH}_{3} \mathrm{CN}(5 \mathrm{~mL})$, r.t. 


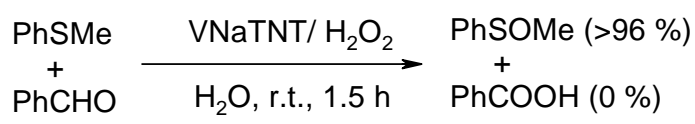

Scheme 2. Formation of methylphenyl sulfoxide from the catalyzed oxidation of methylphenyl sulfide and benzaldehyde.

agreement with our studies.

A set of preliminary experiments on diphenyl sulfide were next performed to examine the effects of different amounts of VNaTNT in $\mathrm{H}_{2} \mathrm{O}$ at $25^{\circ} \mathrm{C}$ (Table 1). No significant oxidation was observed in the absence of VNaTNT in a blank experiment (Table 1, entry 1) and only a low yield of sulfoxide was obtained in the presence of $\mathrm{H}_{2} \mathrm{O}_{2}$ after $6 \mathrm{~h}$. The optimal ratio of sulfide: $\mathrm{H}_{2} \mathrm{O}_{2}: \mathrm{VNaTNT}$ was found to be 2:8:3 for complete conversion of sulfides to sulfoxides. The results are presented in Table 2.

To examine the scope and limitations of this procedure, several functionalized sulfides were selected (Table 2). Dialkyl (1a), aryl alkyl (1b), and diaryl (1c) sulfides could be oxidized to the corresponding sulfoxides in excellent yields. Sulfides with electron-withdrawing (1d, 1e) or donating (1) substituents gave the corresponding solfoxides in excellent yields with high purity. Importantly, this method is compatible with functional groups, such as esters (19). Oxidations could typically be halted at the sulfoxide stage without over-oxidation to the sulfone.

It is evident that the $\mathrm{H}_{2} \mathrm{O}_{2} / \mathrm{VNaTNT}$ system allows these transformations to proceed with excellent selectivity, high yield, and under mild conditions. Furthermore, the use of $\mathrm{H}_{2} \mathrm{O}_{2}$ /VNaTNT makes this method simple, inexpensive, convenient, and practical. Additionally, a competitive $\mathrm{H}_{2} \mathrm{O}_{2} /$ VNaTNT catalyzed oxidation reaction of equimolar amounts of methylphenyl sulfide and benzaldehyde at room temperature leads to the selective formation of methylphenyl sulfoxide in high yield, whereas benzaldehyde remains unchanged (Scheme 2).

The chemoselective oxidation of sulfides to sulfones was also investigated to further demonstrate the efficiency and applicability of the $\mathrm{H}_{2} \mathrm{O}_{2}$ /VNaTNT system. The optimal conditions for the reaction, specified in Table 3, were found using $\mathrm{CH}_{3} \mathrm{CN}$ solvent at ambient temperature (sulfide: $\mathrm{H}_{2} \mathrm{O}_{2}: \mathrm{VNaTNT}=$ 2:15:5). Application of a smaller amount of oxidizing agent gave a mixture of sulfoxide and sulfone. It was found that a wide variety of diaryl, dialkyl, and arylalkyl sulfides have been oxidized to their corresponding sulfones in excellent yields in $\mathrm{CH}_{3} \mathrm{CN}$ at room temperature, as shown in Table 2. Based on a variety of studies, a mechanism, depicted in Scheme 3, has been proposed [3]. The catalytic cycle involves, as a fundamental

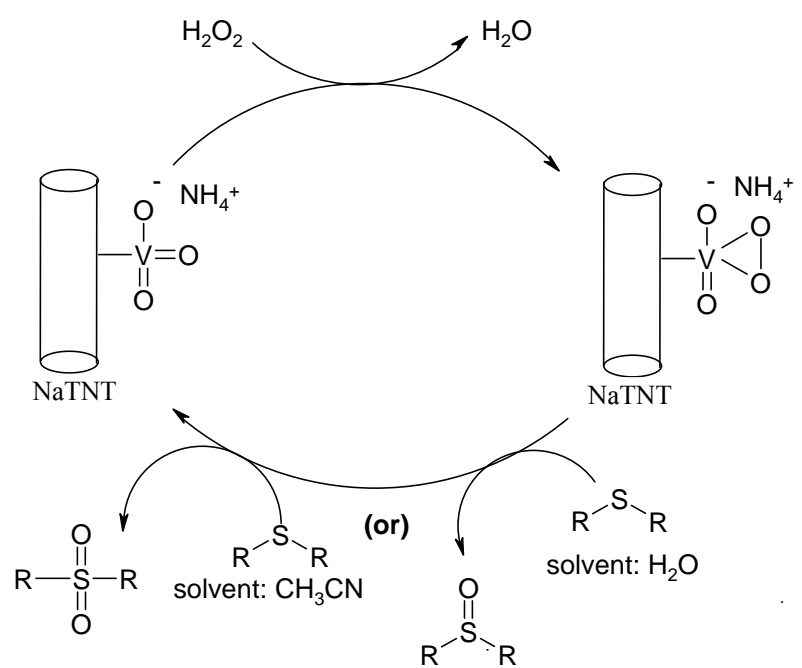

Scheme 3. Simplified catalytic mechanism for the oxidation of sulfides in the presence of $\mathrm{H}_{2} \mathrm{O}_{2} / \mathrm{VNaTNT}$ system.

step, the formation in the active site of a peroxovanadium species (IV) [5], which is a much stronger oxidant than $\mathrm{H}_{2} \mathrm{O}_{2}[3,5]$.

The recovery and reusability of the catalyst have been studied. It was observed that the catalyst can be easily recovered quantitatively by simple filtration after the addition of $\mathrm{CHCl}_{3}$ to the reaction mixture. The wet catalyst was recycled and characterized by neutron activation analysis (NAA), XRD, and FT-IR spectroscopy. The reusability test was carried out under optimized reaction conditions. When the solid catalyst was used for $1,2,3,4$, and 5 cycles, the conversion was $98 \%, 98 \%, 96 \%$, $94 \%$, and $90 \%$, respectively. Therefore, it is possible to reuse the catalyst without significant loss in its activity. Furthermore, no remarkable differences in the morphology of the fresh catalyst and the spent one could be observed. This may be further evidence for the stability of the catalyst. When the reaction was carried out in $\mathrm{MeOH}$, after six runs the vanadium was leached from the support, as proven by SEM and EDX linear scanning along the VNaTNT (Fig. 4(c) and 4(d)), and by NAA and inductively coupled plasma optical emission spectrometry (ICP-OES) results ( $\mathrm{V}$ removed is $0.87 \mathrm{wt} \%$, with deviation in the range of \pm 0.12 ). This led to deactivation of the heterogeneous catalyst.

To show the merit of the present work in comparison with recently reported protocols [44], we compared the results with respect to the amounts of catalyst used, reaction time, and yields of the products (Table 3). Comparison of VNaTNT with these catalysts, for selective oxidation of sulfides to sulfoxides, shows that the activity of VNaTNT seems to be higher than or equal to other known catalysts (Table 3).

Table 3

Comparison of VNaTNT with other catalysts for the oxidation of PhSMe.

\begin{tabular}{|c|c|c|c|c|c|}
\hline Entry & Reagent & Condition & Time (min) & Yield a (\%) & Ref. \\
\hline 1 & Oxidovanadium(V) complexes $/ \mathrm{H}_{2} \mathrm{O}_{2}$ & $\mathrm{CH}_{2} \mathrm{Cl}_{2} / \mathrm{MeOH}$, r.t. & 30 & 88 & [41] \\
\hline 2 & Oxido-bridged dinuclear vanadium(V) Schiff base complexes $/ \mathrm{H}_{2} \mathrm{O}_{2}$ & $\mathrm{CH}_{2} \mathrm{Cl}_{2} / \mathrm{MeOH}$, r.t. & 30 & 88 & [42] \\
\hline 3 & vanadium(V) complexes with tridentate Schiff base ligands $/ \mathrm{H}_{2} \mathrm{O}_{2}$ & $\mathrm{CH}_{2} \mathrm{Cl}_{2} / \mathrm{MeOH}$, r.t. & 30 & 84 & [43] \\
\hline 4 & V@Cr-MIL(101) & EtOH, r.t. & 60 & 98 & [44] \\
\hline 5 & VNaTNT $/ \mathrm{H}_{2} \mathrm{O}_{2}$ & $\mathrm{H}_{2} \mathrm{O}$, r.t. & 30 & 98 & this work \\
\hline
\end{tabular}

aYield refers to the corresponding sulfoxide. 


\section{Graphical Abstract}

Chin. J. Catal., 2016, 37: 494-501 doi: 10.1016/S1872-2067(15)61056-7

\section{Application of sodium titanate nanotubes doped with vanadium (VNaTNT) as a heterogeneous catalyst for oxidation of sulfides at room temperature}

Mohammad Ali Dadvar, Razieh Fazaeli*

Islamic Azad University, Iran

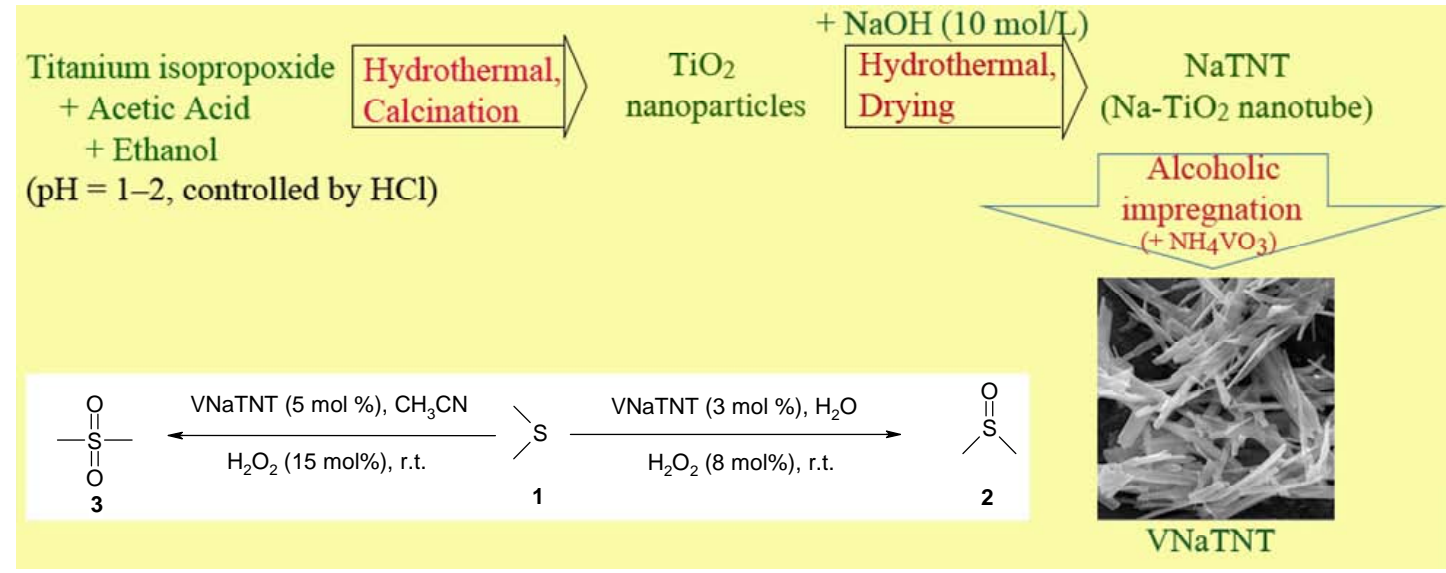

Sodium titanate nanotube doped with vanadium (VNaTNT) has been synthesized, and it showed excellent catalytic performance for the chemoselective oxidation of sulfides in the presence of $30 \% \mathrm{H}_{2} \mathrm{O}_{2}$ in water. FT-IR, XRD, SEM-EDX, TEM, TG, BET and DRUV were used for characterization of the VNaTNT.

\section{Conclusions}

Sodium titanate nanotubes doped with vanadium (VNaTNT) were synthesized by the hydrothermal treatment of a titania nanotube precursor using a alkali solution (10 mol/L) containing both $\mathrm{NaOH}$ and alcoholic $\mathrm{NH}_{4} \mathrm{VO}_{3}$. Vanadium was found to play an important role in the oxidation reactions; therefore, vanadium was added to the sodium titanate nanotubes to improve the catalytic performance. VNaTNT is an excellent heterogeneous system for promoting the highly chemoselective and rapid oxidation of functionalized sulfides with $\mathrm{H}_{2} \mathrm{O}_{2}$ at room temperature in $\mathrm{H}_{2} \mathrm{O}$. It is noteworthy that the reaction tolerates oxidatively sensitive functional groups and the sulfur atom is selectively oxidized.

\section{Acknowledgments}

We gratefully thank Shahreza Branch, Islamic Azad University for financial support.

\section{References}

[1] S. Patai, Z. Rappoport, The Synthesis of Sulphones, Sulphoxides and Cyclic Sulphides, Wiley, New York, 1994, 109-388.

[2] E. Clark, in: J. I. Kroschwitz, M. Howe-Grant, eds., Kirk-Othmer Encyclopedia of Chemical Technology, 4th ed., Wiley, New York, 1997, 23, 134-146.

[3] A. G. J. Ligtenbarg, R. Hage, B. L. Feringa, Coord. Chem. Rev., 2003, 237, 89-101.

[4] V. Palermo, A. G. Sathicq, P. G. Vázquez, G. P. Romanelli, Phospho- rus, Sulfur and Silicon and the Related Elements, 2014, 189, 1423-1432.

[5] V. Conte, A. Coletti, B. Floris, G. Licini, C. Zonta, Coord. Chem. Rev., 2011, 255, 2165-2177.

[6] R. Fazaeli, H. Aliyan, M. Masoudinia, Z. Heidari, J. Mater. Chem. Eng., 2014, 2, 46-55.

[7] R. Fazaeli, H. Aliyan, M.A. Ahmadi, S. Hashemian, Catal. Commun., 2012, 29, 48-52.

[8] J. Fujisaki, K. Matsumoto, K. Matsumoto, T. Katsuki, J. Am. Chem. Soc., 2011, 133, 56-61.

[9] A. M. Khenkin, G. Leitus, R. Neumann, J. Am. Chem. Soc., 2010, 132, 11446-11448.

[10] J. S. Gao, H. C. Guo, S. Z. Liu, M. Wang, Tetrahedron Lett., 2007, 48, 8453-8455.

[11] R. Das, D. Chakraborty, Tetrahedron Lett., 2010, 51, 6255-6258.

[12] R. Das, D. Chakraborty, Synthesis, 2011, 277-280.

[13] D. Chakraborty, P. Malik, V. K. Goda, Appl. Organomet. Chem., 2012, 26, 21-26.

[14] P. Malik, D. Chakraborty, Tetrahedron Lett., 2012, 53, 5652-5655.

[15] R. Fazaeli, H. Aliyan, S. P. Foroushani, Z. Mohagheghian, Z. Heidari, Iran J. Catal., 2013, 3, 129-137.

[16] P. Roy, S. Berger, P. Schmuki, Angew. Chem. Int. Ed., 2011, 50, 2904-2939.

[17] M. Adachi, Y. Murata, M. Harada, S. Yoshikawa, Chem. Lett., 2000, 942-943.

[18] Y. K. Zhou, L. Cao, F. B. Zhang, B. L. He, H. L. Li, J. Electrochem. Soc. A, 2003, 150, 1246-1249.

[19] S. Uchida, R. Chiba, M. Tomiha, N. Masaki, M. Shirai, Electrochemistry, 2002, 70, 418-420.

[20] X. Quan, S. G. Yang, X. L. Ruan, H. M. Zhao, Environ. Sci. Technol., 2005, 39, 3770-3775.

[21] S. H. Kang, J. Y. Kim, Y. Kim, H. S. Kim, Y. E. Sung, J. Phys. Chem. C, 2007, 111, 9614-9623. 
[22] S. Selvam, R. Rajiv Gandhi, J. Suresh, S. Gowri, S. Ravikumar, M. Sundrarajan, Int. J. Pharm., 2012, 434, 366-374.

[23] T. Kasuga, M. Hiramatsu, A. Hoson, T. Sekino, K. Niihara, Adv. Mater., 1999, 11, 1307-1311.

[24] B. C. Viana, O. P. Ferreira, A. G. Souzav Filho, A. A. Hidalgo, J. Mendes Filho, O. L. Alves, Vib. Spectrosc., 2011, 55, 183-187.

[25] P. Hernández-Hipólito, M. García-Castillejos, E. Martínez-Klimova, N. Juárez-Flores, A. Gómez-Cortés, T. E. Klimova, Catal. Today, 2014, 220-222, 4-11.

[26] S. Mozia, E. Borowiak-Palé, J. Przepiórski, B. Grzmil, T. Tsumura, M. Toyoda, J. Grzechulska-Damszel, A. W. Morawski, J. Phys. Chem. Solids, 2010, 71, 263-272.

[27] P. Hernández-Hipólito, N. Juárez-Flores, E. Martínez-Klimova, A. Gómez-Cortés, X. Bokhimi, L. Escobar-Alarcónd, T. E. Klimova, Catal. Today, 2014, 250, 187-196.

[28] T. Kasuga, M. Hiramatsu, A. Hoson, T. Sekino, K. Niihara, Langmuir, 1998, 14, 3160-3163.

[29] E. Morgado Jr., M. A. S. de Abreu, G. T. Moure, B. A. Marinkovic, P. M. Jardim, A. S. Araujo, Chem. Mater., 2007, 19, 665-676.

[30] G. Leofanti, M. Padovan, G. Tozzola, B. Venturelli, Catal. Today, 1998, 41, 207-219.

[31] K. Fan, J. Chen, F. Yang, T. Peng, J. Mater. Chem., 2012, 22, 4681-4186.
[32] K. Siwinska-Stefanska, D. Paukszta, A. Piasecki, T. Jesionowski, Physicochem. Probl. Miner. Process, 2014, 50, 265-276.

[33] H. Lee, J. I. Park, T. H. Kim, K. B. Park, J. Ceram. Process. Res., 2013, 14, 405-409.

[34] J. Y. Cho, W. H. Nam, Y. S. Lim, W. S. Seo, H. H. Park, J. Y. Lee, RSC Adv., 2012, 2, 2449-2453.

[35] G. Catana, R. R. Rao, B. M. Weckhuysen, P. Van Der Voort, E. Vansant, R. A. Schoonheydt, J. Phys. Chem. B, 1998, 102, 8005-8012.

[36] P. Selvam, S. E. Dapurkar, J. Catal., 2005, 229, 64-71.

[37] G. Centi, S. Perathoner, F. Trifiro, A. Aboukais, C. F. Aissi, M. Guelton, J. Phys. Chem., 1992, 96, 2617-2629.

[38] A. Sakthivel, S. E. Dapurkar, P. Selvam, Catal. Lett., 2001, 77, 155-158.

[39] A. T. Vu, Q. T. Nguyen, T. H. L. Bui, M. C. Tran, T. P. Dang, T. K. H. Tran, Adv. Nat. Sci.: Nanosci. Nanotechnol., 2010, 1, 015009/1015009/4.

[40] M. V. Gomez, R. Caballero, E. Vazquez, A. Moreno, A. de la Hoz, A. Diaz-Ortiz, Green Chem., 2007, 9, 331-336.

[41] G. Romanowski, J. Kira, Polyhedron, 2013, 53, 172-178.

[42] G. Romanowski, M. Wera, Polyhedron, 2013, 50, 179-186.

[43] G. Romanowski, J. Mol. Catal. A, 2013, 368-369, 137-144.

[44] R. Fazaeli, H. Aliyan, M. Moghadam, M. Masoudinia, J. Mol. Catal. A, 2013, 374-375, 46-52.

\title{
钒掺杂的钛酸钠纳米管作为多相催化剂用于室温下硫化物的氧化
}

\author{
Mohammad Ali Dadvar, Razieh Fazaeli * \\ 伊斯兰自由大学戈姆分部化学系, 86145-311, 伊朗
}

摘要: 合成了一种含有 $\mathrm{TiO}_{2}, \mathrm{Na}$ 和 $\mathrm{V}$ 的多相纳米管催化剂, 采用红外光谱、 $\mathrm{X}$ 射线衍射、扫描电镜、透射电镜和 $\mathrm{N}_{2}$ 吸附-脱附 法对该催化剂的结构和织构性质进行了表征, 并用于水中 $30 \% \mathrm{H}_{2} \mathrm{O}_{2}$ 选择性氧化硫化物制备对应的亚砜. 该法具有产率极 高、多相体系和简便等优点, 可用于含一系列官能团底物的氧化, 产物分离简便.

关键词: 硫化物; 亚砜; 砜类; 负载型钒催化剂; 纳米管

收稿日期: 2015-12-31. 接受日期: 2016-02-04. 出版日期: 2016-04-05.

*通讯联系人. 电话:+98-31-53292035; 传真: +98-31-53213095; 电子信箱: fazaeli@iaush.ac.ir

本文的英文电子版由Elsevier出版社在ScienceDirect上出版(http://www.sciencedirect.com/science/journal/18722067). 